\title{
VESTIBOLOGY
}

\section{The Video Head Impulse Test in the acute stage of posterior canal benign paroxysmal positional vertigo}

\author{
II Video Head Impulse Test nello stadio acuto della BPPV da canalolitiasi posteriore
}

Luigi Califano, Raffaella lannella, Salvatore Mazzone, Francesca Salafia, Maria Grazia Melillo

San Pio Hospital, Department of Audiology and Phoniatrics, Benevento, Italy

\section{SUMMARY}

Objective. Study the high-frequency vestibulo-oculomotor reflex in posterior canal benign paroxysmal positional vertigo (BPPV) through Video Head Impulse Test (vHIT).

Methods. 150 patients suffering for the first time from posterior canal BPPV were studied. Posterior canal vestibulo ocular reflex (VOR) gain was analysed through stimulations in right anterior-left posterior and left anterior-right posterior planes before treatment, immediately after resolution of the acute stage and one month later. Results were compared with a group of 100 healthy individuals.

Results. No significant difference between the study the control groups was observed, except for normalised asymmetry ratio of the posterior canal which was significantly higher in the study group. VOR gains of both affected posterior canals and contralateral healthy posterior canals were not significantly correlated with the VOR gain of ipsilateral and contralateral anterior canals.

Conclusions. vHIT does not seem to represent an essential tool to study typical posterior canal BPPV in patients affected by this disease for the first time. Different results might be expected in relapsing forms, non-responsive forms, long lasting forms, or atypical variants in which major damage could be provoked by the persistence of otoconia in the canal or by its complete or partial jam.

KEY WORDS: posterior canal BPPV, vHIT, canalolithiasis, vestibulo-oculomotor reflex

\section{RIASSUNTO}

Obiettivo. Valutazione del VOR del canale semicircolare posteriore in fase acuta di VPPB da canalolitiasi posteriore.

Metodi. Valutazione del VOR del canale affetto mediante Video-Head Impulse test in 150 pazienti per la prima volta affetti da VPPB da canalolitiasi posteriore in fase acuta dopo la diagnosi ma prima dell'esecuzione della terapia liberatoria, dopo la risoluzione della fase acuta, un mese dopo la risoluzione. I risultati sono stati confrontati con quelli di un gruppo di 100 persone sane. Risultati. Non sono state riscontrate significative differenze tra gruppo di studio e gruppo di controllo per i guadagni medi del VOR dei canali semicircolari tranne che l'indice normalizzato di asimmetria risultato più alto per i canali posteriori in fase acuta nel gruppo di studio. I guadagni medi del VOR dei canali posteriori affetti e controlaterali sani non appaiono correlati con quelli dei canali anteriori ipsi e controlaterale al canale affetto. Conclusioni. Il vHIT non sembra strumento indispensabile in fase acuta di canalolitiasi posteriore, almeno in una popolazione al primo episodio acuto. Risultati differenti potrebbero essere riscontrati nelle forme recidivanti, resistenti alla terapia, di lunga durata o nelle varianti atipiche in cui la recidivanza, la lunga persistenza degli otoliti nel canale o un jam canalare potrebbero determinare danni maggiori.

PAROLE CHIAVE: BPPV, canalolitiasi posteriore, vHIT, riflesso vestibulo-oculomotore

\section{Introduction}

Benign paroxysmal positional vertigo (BPPV) is the most frequent acute vertigo, accounting for up to $25 \%$ of observations in specialist clinics ${ }^{1}$. The de-
Received: July 29, 2020

Accepted: November 2, 2020

\author{
Correspondence \\ Luigi Califano \\ via A. Lepore 1, 82100 Benevento, Italy \\ Tel. +39082 457407. Fax +39082 457430 \\ E-mail: luigi.califano@tin.it
}

Funding

None.

Conflict of interest

The Authors declare no conflict of interest.

\begin{abstract}
How to cite this article: Califano L, Iannella $\mathrm{R}$, Mazzone $\mathrm{S}$, et al. The Video Head Impulse Test in the acute stage of posterior canal benign paroxysmal positional vertigo. Acta Otorhinolaryngol Ital 2021;41:69-76. https://doi. org/10.14639/0392-100X-N1033
\end{abstract}

(c) Società Italiana di Otorinolaringoiatria e Chirurgia Cervico-Facciale

\section{(c) (1) $(9)$}

This is an open access article distributed in accordance with the CC-BY-NC-ND (Creative Commons Attribution-NonCommercial-NoDerivatives 4.0 International) license. The article can be used by giving appropriate credit and mentioning the license, but only for non-commercial purposes and only in the original version. For further information: https:// creativecommons.org/licenses/by-nc-nd/4.0/deed.en 
tachment of otoconia and complex membranous fragments from the macula of the utriculum and their dislocation in the semicircular canals (SC) are considered to be its most likely pathogenesis. The posterior canal (PC) is involved in $70-90 \%$ of cases, the lateral canal (LC) in $5-30 \%$ and the anterior canal (AC) in 1-5\% ${ }^{1}$. Otoconia may remain freefloating in a canal (canalolithiasis), adhere to the cupula of a canal making it sensitive to gravity (cupulolithiasis), or entirely/partially plugging the canal lumen causing blockage of the endolymphatic flow (canal jam).

Halmagyi and Curthoys ${ }^{2}$ introduced the head impulse test (HIT) in vestibular examination. In its clinical use, the presence of catch-up saccades after a high speed and small amplitude movement of the head is observed by the naked eye immediately after the head impulse, with a specific field of application during acute unilateral vestibular deficit. Video head impulse test (vHIT) ${ }^{3,4}$ is the instrumental evolution of HIT.

vHIT allows clinicians to objectively measure the functional activity of all SC considering both the vestibulo ocular reflex (VOR) gain and the presence of overt or covert saccades to verify whether or not canal function is compromised. vHIT is performed through unpredictable high speed and small amplitude head thrusts in the plane of each co-planar pair of SC: horizontal plane for right and left LCs (L-L plane); LARP plane for Left Anterior and Right Posterior canals; RALP plane for Right Anterior and Left Posterior canals. In LARP and RALP stimulations, the stimulus is along vertical planes, forwards and downwards for $\mathrm{AC}$, and backwards and upwards for $\mathrm{PC}^{4}$.

The literature reports that the study of LC allows evaluation of both VOR gain and possible presence of overt or covert catch-up saccades, whereas for vertical canals clinicians usually consider only the VOR gain, as the data on the refixation saccades in LARP and RALP planes are not yet well replicable 5 .

Few data on vHIT are reported in literature during the acute stage of vertical canals BPPV. Mangabeira Albernaz ${ }^{6}$ reported that in 12/14 cases of BPPV the canal gain was normal, except for a patient with contralateral AC hypofunction, whereas in another case the interpretation was ambiguous due to the coexistence of previous otological disease. Perez-Fernandez ${ }^{7}$ found a normal canal VOR in 12 patients with AC BPPV. Fallahnezhad ${ }^{8}$ reported a decreased gain of the affected PC in 16/29 cases of PC BPPV. Casani ${ }^{9}$ described 2 cases of Lindsay-Hemenway syndrome (PC BPPV arising after an acute unilateral vestibular deficit) ${ }^{10}$, in which the gain of the PC, which is usually not affected in the case of superior vestibular nerve deficit, was decreased. Çınar ${ }^{11}$ reported that in 24 patients with PC BP$\mathrm{PV}$ both the PC gain and the interaural PC gain asymmetry were normal, before and after repositioning manoeuvres, and there were no significant differences with the control population; only $2 / 24$ patients presented a decreased VOR gain of the affected PC. Karawani ${ }^{12}$ found that in $3 / 3$ cases of PC BPPV " $v H I T$ showed injury of the posterior semicircular canal". Aslan ${ }^{13}$ wrote that "20/30 patients who were diagnosed with vertical canal BPPV... had low VOR gains in the vertical canals". In patients with isolated loss of the PC function, Tarnutzer ${ }^{14}$ reported 4 cases of PC BP$\mathrm{PV}$ out of 52 patients with this rare condition. Castellucci ${ }^{15}$ described 3 patients with downbeat positional nystagmus and selective deficit of the VOR gain of the affected PC. Their finding supported the hypothesis of a partial canalith jam in the non-ampullary arm of the affected PC as the cause of the positional downbeat nystagmus.

An abstract has also been presented in which BPPV patients showed a higher VOR gain asymmetry of the vertical canals compared to healthy subjects ${ }^{16}$.

All papers report few or very few cases: the largest series were reported by Çınar ${ }^{11}$, describing 24 cases of PC BP$\mathrm{PV}$, and by Aslan ${ }^{13}$ reporting on 30 cases of vertical canal BPPV. Furthermore, the results of these two studies are not in accordance.

The possible impairment of VOR gain of the vertical canals has also been described in cerebellar lesions, but, in this case, other signs of central suffering are present ${ }^{17}$. Lerchundi described a new syndrome in elderly patients termed "bilateral posterior semicircular canal dysfunction", usually idiopathic, often associated with bilateral sensorineural hearing loss which could present positional downbeat nystagmus. Chronic gait instability is the most common complaint ${ }^{18}$. The possible age-related reduction of PC VOR gain has been previously described by Jimenez ${ }^{19}$.

The aim of our study is to determine if vHIT is a useful diagnostic tool during the first acute episode of typical PC BPPV, evaluating if an altered response of the ampullar receptor is present in PC lithiasis.

\section{Materials and methods}

150 patients with the first diagnosed episode of unilateral PC BPPV were included in the study between January and December 2019 to evaluate the VOR gain of the affected canal through vHIT at three time points: a) during the early acute phase of the disease, prior to treatment with physical manoeuvres; b) immediately after resolution of the acute phase; and c) at one month.

Inclusion criteria were: 1 . Age $>18$ years; 2 . First episode of BPPV; 3. Diagnosis of unilateral PC BPPV; 4. Onset of symptoms within one week prior to the examination; 5. Absence of any relationship between the onset of the 
acute positional vertigo and any trauma (also in the form of an iatrogenic microtrauma, such as dental surgery); 6. Absence of previous acute vertiginous episodes; 7. Absence of other otological/neurological pathologies (Meniere's disease, otosclerosis, VIII cranial nerve schwannoma, vestibular neuritis, significant mono or bilateral hearing loss, demyelinating and neurodegenerative diseases, other rarer diseases); 8. Not migraineurs; 9. Absence of serious visual problems; 10 . Ability to complete vHIT in all the stimulation planes.

The diagnosis of PC BPPV was based on the presence of paroxysmal positional upbeat nystagmus with torsional components beating towards the lowermost ear in ipsilateral Dix-Hallpike positioning, with reversal when returning to the sitting position ${ }^{1}$.

Immediately after diagnosis, in the sitting position, patients underwent vHIT for study of lateral and vertical semi-circular canals function through stimuli on L-L, LARP and RALP planes, using a high-frame-rate (250 frames/sec,) videooculography device (ICS Impulse ${ }^{\circledR}$, Natus Medical) which tests only the right eye. The head mounted camera records eye and head angular velocities: the ratio between the two values is the gain VOR for that stimulation. Twenty artifactfree impulses were considered for LC, and 10 for RALP and LARP planes. The range of velocity for accepted impulses was set at $150-210^{\circ} / \mathrm{sec}$ for the lateral plane, at $110-150 \% \mathrm{sec}$ for the vertical planes. In testing LARP and RALP planes, the horizontal gaze direction must be aligned with the canal plane being tested, otherwise the measured vertical VOR gain decrease could mimic a canal deficit ${ }^{20}$ (Fig. 1). Normative values were obtained in a healthy population of 100 individuals: 44 males, 56 females, considered as a control group. In the case of VOR gain significantly different from the control group (for posterior canal: $0.79 \pm 2 \mathrm{SD}=0.55$, see below), the test was repeated three times, considering the highest measurement for the evaluation.

The mean VOR gain of the affected PC was compared with data from the control group and from the contralateral healthy PC. Normalised asymmetry ratio (NAR) between the gains of the affected PC and of the contralateral healthy PC was calculated using the formula: NAR = (affected canal gain-healthy canal gain)/(affected canal gain+healthy canal gain) x 100 . Consequently, its value is negative when the gain of the affected canal is lower than the gain of the healthy canal, and positive in the opposite case. A difference $\geq 15 \%$ was considered significant. We also analysed the correlations between the PC gain and both ipsilateral $\mathrm{AC}$ and contralateral $\mathrm{AC}$ gains; in the first case the link could be the anatomical contiguity between the ipsilateral PC and AC, and in the second case a functional link could be identified through the push-pull stimulation in LARP and RALP planes.

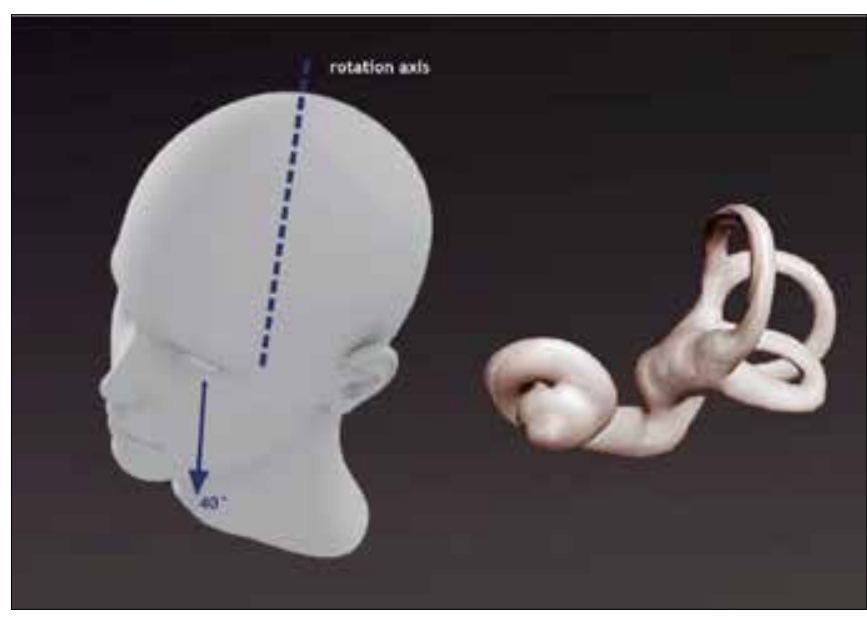

Figure 1. Coplanar orientation of gaze and vertical canals plane during a LARP stimulation (from McGarvie et al. ${ }^{20}$, mod.).

After vHIT, patients underwent the Quick Liberatory Rotation manoeuvre (QLR) ${ }^{21}$. Patients were checked after 3, 7 and 10 days until a negative Dix-Hallpike test was observed. At this point, re-evaluation through vHIT was carried out in all patients. Finally, patients were scheduled for a follow-up evaluation at one month after resolution.

Statistical analysis was performed with descriptive statistics and confidence intervals of a mean, unpaired T-test, Pearson correlation test and Grubbs' test to detect an outlier, with significance level set at $0.05,95 \%$ confidence interval, using Graph pad Quick Calcs software. The statistical power analysis was calculated both through Satorra and Saris's method - Structural Equation Model based on the Chi-squared test ${ }^{22}-$ (good statistical power if power value $\geq 0.80$ ) and through MacCallum's method- Structural Equation Model based on Root-Mean-Square Error of Approximation (RMSEA) ${ }^{23}-$ (good fitting of the proposed model with RMSEA $\leq 0.8$ ).

All procedures were in accordance with the ethical standards of the Ethics Review Board and with the 1964 Helsinki declaration and its later amendments.

\section{Results}

The control group consisted of 100 individuals, 56 females and 44 males, with a F/M ratio of 1.27 and a mean age of $58 . \pm 13.21$ years (range 19-81 years, median 59.5 years).

\section{vHIT assessment}

LC: mean VOR gain $0.99 \pm 0,113$; PC: mean VOR gain $0.79 \pm 0.121$; AC: mean VOR gain $0.73 \pm 0.094$. Differences between the age classes were not significant, except for patients $>75$ years. In this subgroup ( 8 patients), the mean 
VOR gain of LC was $1.06 \pm 0.051$, which was significantly higher than the mean VOR gain of LC in individuals $<75$ years $(0.98 \pm 0,101, p=0.028)$. In 5 of $200 \mathrm{PC}$, the gain was between 0.56 and 0.60 . No outlier was detected. Mean NAR between right and left PC was $3.8 \pm 7.76$. The maximum NAR was $13.1 \%$ (absolute value). The correlations between the mean VOR gain of PC and the mean VOR gains of both the ipsilateral $\mathrm{AC}$ and the contralateral $\mathrm{AC}$ were weak and not significant, for both ipsilateral PC and $\mathrm{AC}(\mathrm{r}=0.1235 ; \mathrm{p}=0.10561)$, and for PC and contralateral $\mathrm{AC}(\mathrm{r}=0.0987: \mathrm{p}=0.16754)$.

The study group consisted of 150 patients, 91 females and 59 males, with a F/M ratio of 1.54, and a mean age of $60.6 \pm 13.16$ years (range 19-91 years, median 59 years). The mean age was not significantly different from the control group $(\mathrm{p}=0.95)$. Statistical power for Structural Equation Model based on Chi-squared test was 0.8, RMSEA was 0.05 .

\section{vHIT: pre-treatment assessment}

The mean VOR gains were: $0.75 \pm 0.152$ for the affected PC; $0.81 \pm 0.113$ for the healthy PC; $0.71 \pm 0.098$ for AC; $0.98 \pm 0.124$ for LC. In $10 / 150$ patients $(6.7 \%)$ the VOR gain of the affected PC was $\leq 0.55$ (range 0.36-0.50), i.e. two standard deviations less than the mean PC VOR gain of the control group; in two of these patients (both were $>70$ years) the healthy contralateral PC VOR gain was also $\leq 0.55$. Only one case among the VOR gains of the affected PC was considered as furthest from the other values, but was not a significant outlier. Mean VOR gain differences between both the affected PC and the contralateral healthy $\mathrm{PC} v s$ the control group were not significant (respectively, $p=0.33 ; p=0.18$ ). The mean VOR gain difference between the affected PCs and the healthy contralateral canals was significant $(p=0.01)$ due to the mild mean VOR gain increase of the non-affected PC and the mild mean VOR gain decrease of the affected PC compared to the PC mean VOR gain of the control group. The mean NAR between affected and healthy PC was $-7.1 \pm 9.65$ (range from $-38.6 \%$ to $+6.9 \%$ ), which was significantly different from the control group ( $\mathrm{p}=0.004)$. The correlation between the mean VOR gains of $\mathrm{AC}$ and $\mathrm{PC}$ was weakly positive, but not significant: for ipsilateral PC and AC, $r=0.178 ; \mathrm{p}=0.4$; for LARP and RALP $r=0.24076, p=0.1$. In the study group, overt catchup saccades in the affected PC plane were observed in six patients with the lowest observed VOR gains (Fig. 2). The mean number of liberatory manoeuvres necessary to cure PC BPPV was not significantly different between the subgroup with either normal or not far from the normal VOR gain- within 1 standard deviation (140 patients), and the subgroup of 10 patients with PC VOR gain $\leq 0.55$, which was far more than 2 standard deviations from the normal value (mean: $2.04 \pm 0.65$ vs $2.06 \pm 0,74, \mathrm{p}=0.9$ ).

Data of pre-treatment assessment from the control and study groups are reported in Table I.

\section{vHIT: post-treatment assessment}

The mean VOR gains were $0.77 \pm 0.127$ for treated PC; $0.81 \pm 0.161$ for healthy PC; $0.73 \pm 0.144$ for AC; $0.98 \pm 0.212$ for LC. In $9 / 10$ cases with pre-treatment VOR gain of the affected $\mathrm{PC} \leq 0.55$, VOR gain improved but did not reach a normal level (new range: 0.57-0.64); in the lattest case the post-treatment gain was normal $(0.74$, pretreatment value: 0.36 ). The mean VOR gain difference between pre-treatment and post-treatment values of the affected PC was not significant $(0.77$ vs $0.75, \mathrm{p}=0.5)$, whereas

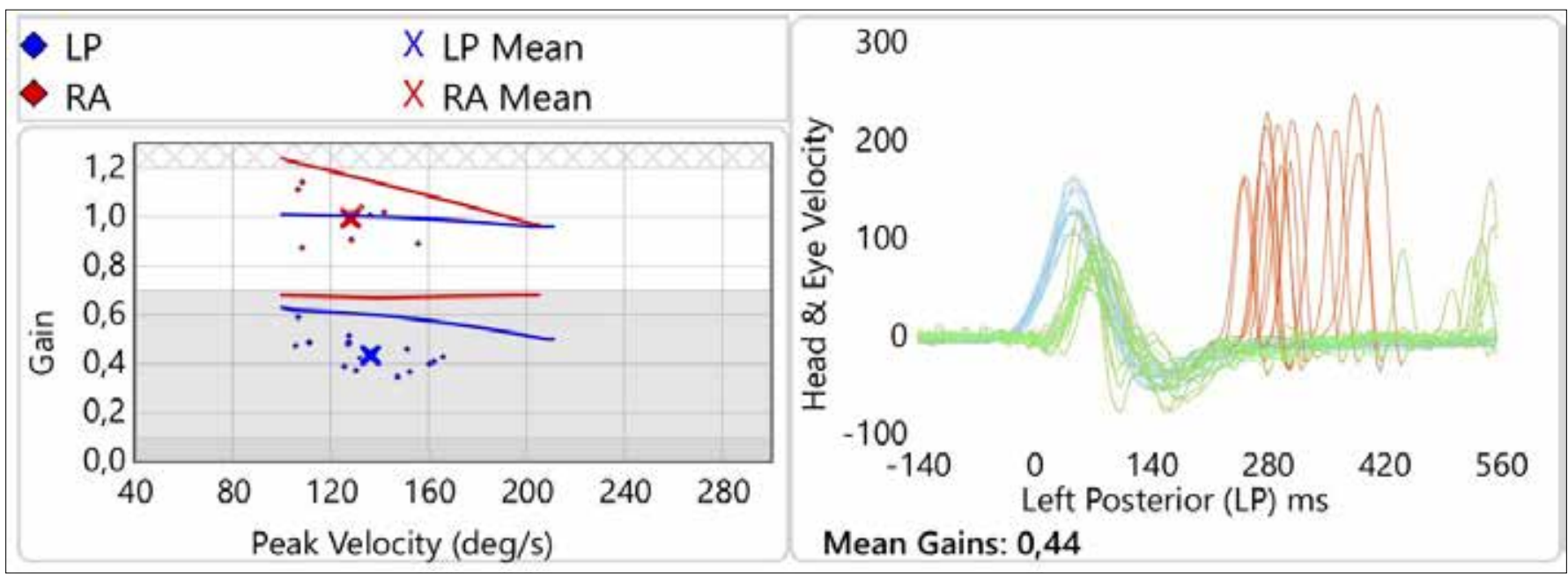

Figure 2. vHIT: a case of low VOR gain in an acute left posterior canal BPPV with overt scattered catch-up saccades. 
Table I. VHIT assessment in the control and study groups (pre-treatment assessment).

\begin{tabular}{lcccc} 
& $\begin{array}{c}\text { Lateral canal mean VOR } \\
\text { gain }\end{array}$ & $\begin{array}{c}\text { Affected posterior canal } \\
\text { mean VOR gain }\end{array}$ & $\begin{array}{c}\text { Healthy posterior canal } \\
\text { mean VOR gain }\end{array}$ & $\begin{array}{c}\text { Anterior canal } \\
\text { mean VOR gain }\end{array}$ \\
Control group & $0.99 \pm 0.113$ & - & $0.79 \pm 0.121$ & $0.73 \pm 0.094$ \\
Study group & $0.98 \pm 0.124$ & $0.75 \pm 0.152^{*}$ & $0.81 \pm 0.113^{*}$ & $0.71 \pm 0.098$ \\
\hline
\end{tabular}

${ }^{*}$ Significant difference in the study group between VOR gains of affected vs. healthy posterior canals ( $\left.p=0.01\right)$. Differences between VOR gains of all semi-circular canals in the control vs. study groups are not significant.

the difference with the mean VOR gain of contralateral nonaffected PC remained significant ( 0.77 vs. $0.81, \mathrm{p}=0.04$ ). No outlier was detected. The mean NAR between affected and healthy PC was $-5.4 \pm 7.0$, which was not significantly different from the pre-treatment value $(\mathrm{p}=0.156)$ and not significant compared to the control group $(\mathrm{p}=0.09)$.

In both the pre-treatment and post-treatment assessments, no significant difference was observed between the gains of AC and LC in the control and study, and in the VOR gain differences for age classes for vertical canals, whereas the difference was not significant for LC in the subgroup $>75$ years (15 patients), in which the mean VOR gain was higher $(\mathrm{p}=0.07)$.

\section{One-month assessment}

82 patients attended the scheduled examination. All were disease-free at Dix-Hallpike test; three reported mild residual dizziness. The mean VOR gains were $0.78 \pm 0.215$ for the treated PC; $0.80 \pm 0.248$ for the healthy PC; $0.73 \pm 0.199$ for AC; $0.98 \pm 0.178$ for LC. In 3 cases with pre-treatment VOR gain of the affected PC $\leq 0.55$, VOR gain was normal (new range: $0.71-0.77$ ). No outlier was detected. The difference between the mean VOR gains of affected and healthy PC was no longer significant $(\mathrm{p}=0.58)$. The mean NAR between treated and healthy PC was $-4.9 \pm 8.4$, not significantly different from the control group $(p=0.36)$ and from the pre-treatment value $(\mathrm{p}=0.11)$. Data of PC VOR gain in the study group are summarised in Table II.

\section{Discussion}

BPPV is the most frequent acute vertigo and detachment of otoconia from the utricular macula is considered the under- lying pathophysiologic mechanism. Otoconia can be either free-floating in a semicircular canal or adherent to a semicircular canal cupula; rarely they can provoke a "canal jam". Since 2001 the possible role of the canal jam in some forms of canalolithiasis has been reported ${ }^{24}$. Later, other authors reported the same mechanism in rare cases of positional vertigo. Luis ${ }^{25}$ reported a case of direction-fixed nystagmus lateral canal BPPV characterised by a deficiency of the cupular-endolymph high-frequency system dynamics due to the presence of a block of the endolymphatic flow in the affected canal. The deficiency was resolved after success of the liberatory manoeuvre. Castellucci ${ }^{26}$ described an analogous case with isolated lateral canal hypofunction, ascribed to a canal jam, that was resolved by repeated head shaking and conversion into a typical geotropic LC BPPV. Schubert ${ }^{27}$ considered that in some cases of direction-fixed nystagmus LC BPPV, the otoconial jam acts as a "false" cupula, which causes a modification in velocity but not in the direction of the nystagmus that depends on head position. As already mentioned, Castellucci ${ }^{15}$ described also some cases regarding the vertical canals. In these cases, the authors' interpretation was that a canal jam in the nonampullary tract of the PC caused a partial block of the endolymphatic flow. Acting as a "low-pass filter", the jam allowed cupular activation by otoconia movements but not a good cupular response to high frequency impulses, as in vHIT. Obviously, this mechanism may be applied both to LC BPPV and to PC BPPV. Thus, the canal jam would act by modifying the endolymphatic dynamics of the affected canal.

Except in the specific case of a presumed canal jam, which is theoretically conceivable in only a small minority of cases, pathogenetic hypotheses involving mechanic factors

Table II. VHIT assessment of the posterior canal in the study group.

\begin{tabular}{lcc} 
& $\begin{array}{c}\text { Affected posterior canal } \\
\text { Mean VOR gain }\end{array}$ & $\begin{array}{c}\text { Healthy posterior canal } \\
\text { Mean VOR gain }\end{array}$ \\
Pre-treatment & $0.75 \pm 0.152^{*}$ & $0.81 \pm 0.113^{*}$ \\
Post-treatment & $0.77 \pm 0.127^{* *}$ & $0.81 \pm 0.161^{* *}$ \\
One-month evaluation & $0.78 \pm 0.215^{* * *}$ & $0.80 \pm 0.248^{* * *}$ \\
\hline
\end{tabular}

Significant differences in the study group between VOR gains of affected vs. healthy posterior canals in pretreatment evaluation and immediate post-treatment evaluation $\left(p=0.01 ;{ }^{* *} p=0.04\right)$. Not significant difference at the one-month evaluation (" $\left.p=0.58\right)$. 
give no immediate answer about a possible VOR gain impairment of the affected canal.

Caloric and rotatory techniques have been used to approach the problem. A transient caloric hypofunction was pointed out in the case of LC BPPV ${ }^{28}$. A strong cold-water caloric stimulus $\left(24^{\circ} \mathrm{C}\right)$ had a significant inhibitory effect on the ipsilateral horizontal high-acceleration VOR-gain, assessed with vHIT, emphasising the importance of the non-linear pathway when vestibular organs are probed with highacceleration stimuli ${ }^{29}$. These data were also confirmed through cold stimulation in the prone position, which has physiologic excitatory effects on LC cupula. This might occur because the cupular deviation in either direction elicits a partial mechanical and electrophysiological saturation, decreasing cupular sensitivity with respect to high acceleration stimuli ${ }^{30}$. In 6 patients with PC BPPV, the pendular rotation test in a head-tilted position gave a lower response of $\mathrm{PC}$ respect to $\mathrm{AC}^{31}$. In patients with BPPV, during a sinusoidal rotation VOR gains of the vertical canals were not changed in comparison with normal subjects ${ }^{32}$.

Since 2013, the availability to test all six semi-circular canals through vHIT has allowed clinicians to evaluate the VOR gain for each of them, using specific planar stimuli: L-L plane for LC, LARP plane for Left AC and Right PC, RALP plane for Right AC and Left PC ${ }^{4}$. At present, vHIT is probably the most effective tool to evaluate the semi-circular canals function.

The high incidence of PC BPPV opened a window to study PC function during the acute stage of the disease with vHIT. So far, few papers have been published on this topic. As mentioned, a limited number of cases have been reported, with contrasting results about the functional impairment of PC activity. Fallahnezhad ${ }^{8}$, Karawani ${ }^{12}$ and Aslan ${ }^{13}$ reported a significant lowering of PC VOR gain during the acute stage of PC BPPV. Data from Casani ${ }^{9}$ in two cases of Lindsay-Hemenway syndrome are not easily understandable: the reported posterior canal VOR gain deficit could be due either to the previous acute vestibular neuritis as in our opinion as the Authors meant or it could be due to a secondary canalolithiasis. It is also worth mentioning the data reported by Castellucci et al. ${ }^{15}$ about a rare variant, apogeotropic PC BPPV, in which, at least in some cases, a $\mathrm{PC}$ incomplete jam could be hypothesised. In their cases, vHIT was also a useful tool to discriminate between the involvement of either the PC or the contralateral AC.

In typical PC BPPV, the mechanism provoking the paroxysmal nystagmus is considered to be ampullophugal endolymphatic flow in the affected PC induced by the free floating otoconia movement away from the cupula towards the most inferior portion of the canal during Dix-Hallpike test. According to Ewald's II law, ampullophugal flow excites the PC cupular receptor to provoke specific oculomotor reflex responses through the activation of the contralateral superior rectus and ipsilateral inferior obliquus muscles, responsible for the fast phase vectors.

Does damage to the PC ampulla actually exist or should abnormal responses be considered as a result of an anomalous stimulus acting on a normal receptor? In other words, are we discussing of a purely mechanical disorder of the inner ear or does the mechanical disorder provoke either deficient or irritative responses of the ampullar receptor?

We analysed 150 patients exhibiting the first episode of typical PC-BPPV. Mean VOR gains of all semi-circular canals were not significantly different between the study and control. In particular, in the pre-treatment phase, the mean VOR gain of the affected PC was not significantly different compared to the control group ( $\mathrm{p}=0.33)$, but significantly lower than the mean VOR gain of the healthy contralateral PC $(p=0.01)$; this significant difference was also maintained in the post-treatment phase $(\mathrm{p}=0.04)$, despite a mild increment in the mean VOR gain of the affected PC, which was not significant with respect to the pre-treatment assessment $(\mathrm{p}=0.5)$. At the one-month evaluation, the difference between the mean VOR gains of affected and healthy PC was no longer significant ( $p=0.58$ ).

According to our results, PC VOR gain does not seem to be significantly affected in patients with typical PC BPPV, but in a small subgroup of 10 patients $(6.7 \%)$ with a different behaviour it does exist. In these cases, the PC VOR gain was $\leq 0.55$, our cut-off value for a clearly impaired $\mathrm{PC}$ function, within a range of 0.36-0.50, and, interestingly, after the resolution of the acute phase, it improved in all patients. It appears likely that in these cases the VOR gain deficit was directly due to the canalolithiasis effects on the ampullar receptor stimulation. In 2 patients $>70$ years with bilateral PC VOR gain $<0.55$, a possible age related reduction of PC VOR gain ${ }^{19}$ was considered possible, but the successive normalisation of the values during the follow-up excluded this diagnosis.

The correlation of the mean VOR gain of AC with the mean VOR gain of the affected PC was weakly positive but not significant, as also seen in the control group. This means that both the ipsilateral AC in a possible anatomical contiguity relationship and the contralateral $\mathrm{AC}$ in a possible functional relationship during LARP and RALP push-pull stimulations seem to be functionally unaffected by the hydrodynamic changes induced by PC canalolithiasis.

Our data suggest that in the acute phase of PC BPPV there is usually no alteration in the canal receptor response as shown by the normality of the affected PC mean VOR gain, as in the control group. Paroxysmal positioning nystagmus, which is the primary sign of the disease, has to be inter- 
preted as being due to a normal receptor response to an abnormal stimulus, and not to receptor dysfunction in terms of either canalar hyporeflexia or hyperreflexia.

However, a minority of cases (6.7\%) in which the PC VOR gain was significantly reduced, it does exist, with a trend in recovery immediately after resolution of the disease through a liberatory manoeuvre. These cases did not show any difference in the quantitative and qualitative features of the diagnostic paroxysmal positioning nystagmus, as evidence of the preserved ability of the receptor to respond to the stimulus caused by the otoconial movement in the canal. It is therefore likely that in these cases the reduced response may be related to the presence of otoconia in the canal determining in a sitting position a reduction of the stimulus provided during vHIT. In fact, at post-treatment assessment an improvement of the affected PC VOR gain was observed in all cases, and in one case even its normalisation, whereas at the one-month visit all PC VOR gains were normal.

The significant difference between the mean VOR gains of the affected PC and the contralateral PC, in both pretreatment and immediate post-treatment assessments, is not easily justifiable. The pair of PC does not respond to the same push-pull stimulus, so that a decrease of the inhibitory stimulus of a weaker affected canal cannot be hypothesised when it is in a "pull" situation during vHIT, as well as the responses of the $\mathrm{AC}$ of the affected side, which is the canal functionally related with the contralateral PC during LARP and RALP planes stimulations, were normal. Again, the data cannot be justified by the decrease of the inhibitory quota on the global response in either the LARP or in the RALP planes provided by a normal contralateral AC when PC is stimulated. However, even if in a numerically smaller population, the difference between affected and healthy PCs was no longer significant at the one-month control.

It should also be noted that our series relates to people suffering for the first time from acute BPPV. It cannot be excluded that in a differently selected population, i.e. subjects with multiple recurrence of the disease, the situation of the canal receptor may be different. We believe that future clinical series should take this potential diversity into account.

\section{Conclusions}

vHIT appears to play an ancillary role in the clinical management of patients suffering from acute PC BPPV. However, vHIT can provide useful data for better understanding of the pathology, identify possible otological comorbidities, help to identify the affected canal, and can have forensic value in highlighting possible persistent canal damage. Keeping in mind these considerations, its routine perfor- mance in acute PC BPPV does not appear to be clinically essential, recalling, however, the selected population of our study and the current limit that there are still very limited data in the literature regarding vHIT results in frequently recurrent forms, in long-term forms, in non-responsive forms, in atypical variants, which are specific issues in which this test could have relevance. In these cases, hypothetically, otoconia could be either partially entrapped or embedded in some narrow portion of the affected canal causing their anomalous evolution. Interesting and perhaps different data could be obtained in forms we could label as "cupulolithiasis" in which the PC receptor could be more directly affected. The scientific method is based on hypotheses and their demonstration: all hypotheses need objective data to be supported. Ad hoc studies in those subgroups are thus required. Nonetheless, even in typical PC BPPV, the information provided by vHIT is definitely useful for a more complete assessment of the vertiginous patient.

\section{References}

1 Von Brevern M, Bertholon P, Brandt T, et al. Benign paroxysmal positional vertigo: diagnostic criteria. Consensus document of the Committee for the Classification of Vestibular Disorders of the Bárány Society. J Vestib Res 2015;25;105-17. https://doi.org/10.3233/VES-150553

2 Halmagyi GM, Curthoys IS. A clinical sign of canal paresis. Arch Neurol 1988;45:737-9. https://doi.org/10.1001/archneur.1988.00520310043015

3 MacDougall HG, Weber KP, McGarvie LA, et al. The video head impulse test diagnostic accuracy in peripheral vestibulopathy. Neurology 2009;73:1134-41. https://doi.org/10.1212/WNL.0b013e3181bacf85

4 MacDougall HG, McGarvie LA, Halmagyi GM, et al. Application of the video head impulse test to detect vertical semicircular canal dysfunction. Otol Neurotol 2013;34:974-9. https://doi.org/10.1097/ MAO.0b013e31828d676d

5 Singh NK, Govindaswamy R, Jagadish NV. Test-retest reliability of video head impulse test in healthy individuals and individuals with dizziness. J Am Acad Audiol 2019;30:744-52. https://doi. org/10.3766/jaaa.17080

6 Mangabeira Albernaz PL, Zuma E Maia FC. The video head impulse test. Acta Otolaryngol 2014;134:1245-50. https://doi.org/10.3109/00 016489.2014.942439

7 Perez-Fernandez N, Martinez-Lopez M, Manrique-Huarte R. Vestibulo-ocular reflex in patients with superior semicircular canal benign paroxysmal positional vertigo (BPPV). Acta Oto-Laryngologica 2014;134:485-90. https://doi.org/10.3109/00016489.2013.871750.

8 Fallahnezhad T, Ghahraman MA, Farahani S, et al. Vestibulo-ocular reflex abnormalities in posterior semicircular canal benign paroxysmal positional vertigo: a pilot study. Iran J Otorhinolaryngol 2017;29:269-74.

9 Casani AP, Cerchiai N, Navari E. Paroxysmal positional vertigo despite complete vestibular impairment: the role of instrumental assessment. Acta Otorhinolaryngol Ital 2018;38:563-8. https://doi. org/10.14639/0392-100X-1549

10 Hemenway W, Lindsay J. Postural vertigo due to unilateral sudden partial loss of vestibular function. Ann Otol Rhinol Laryngol 1956;65:692-706. https://doi.org/10.1177/000348945606500311

11 Çınar Y, Bayram A, Culfa R, et al. Analyses with the video head 
impulse test during the canalith repositioning maneuver in patients with isolated posterior semicircular canal benign paroxysmal positional vertigo. Turk Arch Otorhinolaryngol 2018;56:81-4. https://doi. org/10.5152/tao.2018.3166

12 Karawani K, Bielińska M, Nowosielska-Grygiel J, et al. Comparative evaluation of the diagnostic value of the VHIT and Dix-Hallpike test in patients with balance system disorders in out-patient healthcare practice and expertise preparation. Otolaryngol Pol 2018;72:36-42. https://doi.org/10.5604/01.3001.0012.5421

13 Aslan H, Pinar E, Aladağ İ, et al. Our results of VHIT on BPPV. Eur J Rhinol Allergy 2018;1:12-4. https://doi.org/10.5152/ejra.2018.56708

14 Tarnutzer AA, Bockisch CJ, Buffone E, et al. Association of posterior semicircular canal hypofunction on video-head-impulse testing with other vestibulo-cochlear deficits. Clin Neurophysiol 2017;128:153241. https://doi.org/10.1016/j.clinph.2017.04.029

15 Castellucci A, Malara P, Delmonte S, et al. A possible role of video-head impulse test in detecting canal involvement in benign paroxysmal positional vertigo presenting with positional downbeat nystagmus. Otol Neurotol 2020;41:386-91. https://doi.org/10.1097/ MAO.0000000000002500

16 Guan Q, Zhang L, Hong W, et al. Video head impulse test for evaluation of vestibular function in patients with vestibular neuritis and benign paroxysmal positional vertigo. J Zhejiang Univ (Med Sci) 2017;46:52-8.

17 Choi J-Y, Kim H-J, Kim J-S. Recent advances in head impulse test findings in central vestibular disorders. Neurology 2018;90:602-12. https://doi.org/10.1212/WNL.0000000000005206

18 Lerchundi F, Laffue AH, Olivier M, et al. Bilateral posterior semicircular canal dysfunction: a new finding with video head impulse test. J Neurol 2020;267:2347-52. https://doi.org/10.1007/s00415020-09793-5

19 Jiménez GG, Pérez Fernandez N. Reducción de la ganancia del canal semicircular posterior en el test del impulso cefálico con la edad. Estudio observacional. Acta Otorrinolaringol Esp 2016;67:15-22. https://doi.org/10.1016/j.otorri.2014.12.002

20 McGarvie LA, Martinez-Lopez M, Burgess AM, et al. Horizontal eye position affects measured vertical VOR gain on the video head impulse test. Front Neurol 2015;6:58. https://doi.org/10.3389/ fneur.2015.00058

21 Califano L, Capparuccia PGG, Di Maria D, et al. Treatment of benign paroxysmal positional vertigo of posterior semicircular canal by
"Quick Liberatory Rotation Manoeuvre". Acta Otorhinolaryngol Ital 2003;23:161-7.

22 Satorra A, Saris WE. Power of the likelihood ratio test in covariance structure analysis. Psychometrika 1985;50:83-90. https://doi. org/10.1007/BF02294150

23 MacCallum RC, Browne MW, Sugawara HM. Power analysis and determination of sample size for covariance structure modeling. Psychol Methods 1996;1:130-49. https://doi.org/10.1037/1082-989X.1.2.130

24 von Brevern M, Clarke AH, Lempert T. Continuous vertigo and spontaneous nystagmus due to canalolithiasis of the horizontal canal. Neurology 2001;56:684-6. https://doi.org/10.1212/wnl.56.5.684

25 Luis L, Costa J, Vaz Garcia F, et al. Spontaneous plugging of the horizontal semicircular canal with reversible canal dysfunction and recovery of vestibular evoked myogenic potentials. Otol Neurotol 2013;34:743-7. https://doi.org/10.1097/MAO.0b013e318287f343

26 Castellucci A, Malara P, Brandolini C, et al. Isolated horizontal canal hypofunction differentiating a canalith jam from an acute peripheral vestibular loss. Am J Otolaryngol 2019;40:319-22. https://doi. org/10.1016/j.amjoto.2018.12.005

27 Schubert MC, Helminski J, Zee DS, et al. Horizontal semicircular canal jam: two new cases and possible mechanisms. Laryngoscope Investig Otolaryngol 2020;5:163-7. https://doi.org/10.1002/lio2.352

28 Domènech Campos E, Armengol Canceller M, Barona de Guzman R. Vértigo posicional paroxístico benigno del canal horizontal. Acta Otorinolaringol Esp 2006;57:446-9. https://doi.org/10.1016/s00016519(06)78746-5

29 Tamás LT, Weber KP, Bockisch CJ, et al. Cold thermal irrigation decreases the ipsilateral gain of the vestibulo-ocular reflex. Ear Hear 2017;38:e193-e9. https://doi.org/10.1097/AUD.0000000000000398

30 Tamás LT, Obrist D, Avan P, et al. Biasing the semicircular canal cupula in excitatory direction decreases the gain of the vestibuloocular reflex for head impulses. J Vestib Res 2019;29:281-6. https://doi. org/10.3233/VES-190681

31 IIda M, Igarashi M, Naitoh A, et al. Evaluation of the vertical canal function by the pendular rotation test: a study on patients with benign paroxysmal positional vertigo. ORL J Otorhinolaryngol Suppl 1997;59:269-71. https://doi.org/10.1159/000276951

32 Sekine $\mathrm{K}$, Imai $\mathrm{T}$, Morita $\mathrm{M}$, et al. Vertical canal function in normal subjects and patients with benign paroxysmal positional vertigo. Acta Otolaryngol 2004;124:1046-52. https://doi. org/10.1080/00016480410018061 